\title{
Radio occultation bending angle anomalies during tropical cyclones
}

\author{
R. Biondi ${ }^{1}$, T. Neubert ${ }^{1}$, S. Syndergaard ${ }^{2}$, and J. K. Nielsen ${ }^{2}$ \\ ${ }^{1}$ DTU Space, National Space Institute, Copenhagen, Denmark \\ ${ }^{2}$ DMI, Danish Meteorological Institute, Copenhagen, Denmark
}

Received: 27 January 2011 - Published in Atmos. Meas. Tech. Discuss.: 28 February 2011

Revised: 23 May 2011 - Accepted: 3 June 2011 - Published: 15 June 2011

\begin{abstract}
The tropical deep convection affects the radiation balance of the atmosphere changing the water vapor mixing ratio and the temperature of the upper troposphere lower stratosphere. The aim of this work is to better understand these processes and to investigate if severe storms leave a significant signature in radio occultation profiles in the tropical tropopause layer. Using tropical cyclone best track database and data from different GPS radio occultation missions (COSMIC, GRACE, CHAMP, SACC and GPSMET), we selected 1194 profiles in a time window of $3 \mathrm{~h}$ and a space window of $300 \mathrm{~km}$ from the eye of the cyclone. We show that the bending angle anomaly of a GPS radio occultation signal is typically larger than the climatology in the upper troposphere and lower stratosphere and that a double tropopause during deep convection can easily be detected using this technique. Comparisons with co-located radiosondes, climatology of tropopause altitudes and GOES analyses are also shown to support the hypothesis that the bending angle anomaly can be used as an indicator of convective towers. The results are discussed in connection to the GPS radio occultation receiver which will be part of the Atomic Clock Ensemble in Space (ACES) payload on the International Space Station.
\end{abstract}

\section{Introduction}

Deep convective systems influence global circulation and the mass exchange between the troposphere and stratosphere (Fueglistaler et al., 2009), and they also have been recognized as a crucial process for the understanding of the climate changes. Temperature and water vapour variation in the upper troposphere and lower stratosphere (UTLS) are

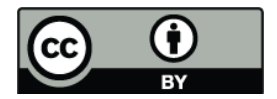

Correspondence to: $\mathrm{R}$. Biondi (ribi@space.dtu.dk) closely connected to the convection (Danielsen, 1982; Sherwood et al., 2003; Chae et al., 2011) but the difficulty to measure those parameters at such altitudes, with high vertical resolution and sensitivity still raises many questions on their behaviour (Forster and Shine, 1999). The stratospheric water vapour, like the $\mathrm{CO}_{2}$, is a greenhouse gas contributing to the global warming (Manabe and Wetherald, 1967; Soden and Fu, 1995; Forster and Shine, 2002; Solomon et al., 2010) and the variation of temperature in the tropical tropopause layer (TTL) during the convection is strictly linked to the variation of water vapor overshooted by the storm (Kim, 2005). The tropical cyclones (TCs) are severe weather events often leading to deep convective activity and persisting for long time. They alter the physics and chemistry of the TTL and they play a fundamental role on the atmospheric circulation and troposphere-stratosphere exchange (Ray and Rosenlof, 2007; Cairo et al., 2008; Fueglistaler et al., 2009; Romps and Kuang, 2009). The GPS Radio Occultation (RO) technique (Kursinki et al., 1997) is useful to study severe weather phenomena because the GPS signal is independent on the weather conditions and it allows profiling atmospheric parameters with high vertical resolution and accuracy. The past and ongoing GPS RO missions, Global Positioning System/Meteorology (GPS/MET) satellite (Rocken et al., 1997), the CHAllenging Minisatellite Payload (CHAMP) satellite (Wickert et al., 2001), the Satellite de Aplicaciones Cientificas-C (SAC-C) satellite (Hajj et al., 2004), the Constellation Observing System for Meteorology, Ionosphere and Climate (COSMIC) six-satellite constellation (Anthes et al., 2008), and the Gravity Recovery And Climate Experiment (GRACE) twin satellites (Beyerle et al., 2005), have a denser number of measurements at mid and high latitude due to the inclination of the orbits, but they do not provide a good coverage of the tropical area (Fig. 1). A new advanced GPS receiver is planned to be launched in the near future on board of the International Space Station (ISS) as part of the Atomic Clock Ensemble in Space

Published by Copernicus Publications on behalf of the European Geosciences Union. 


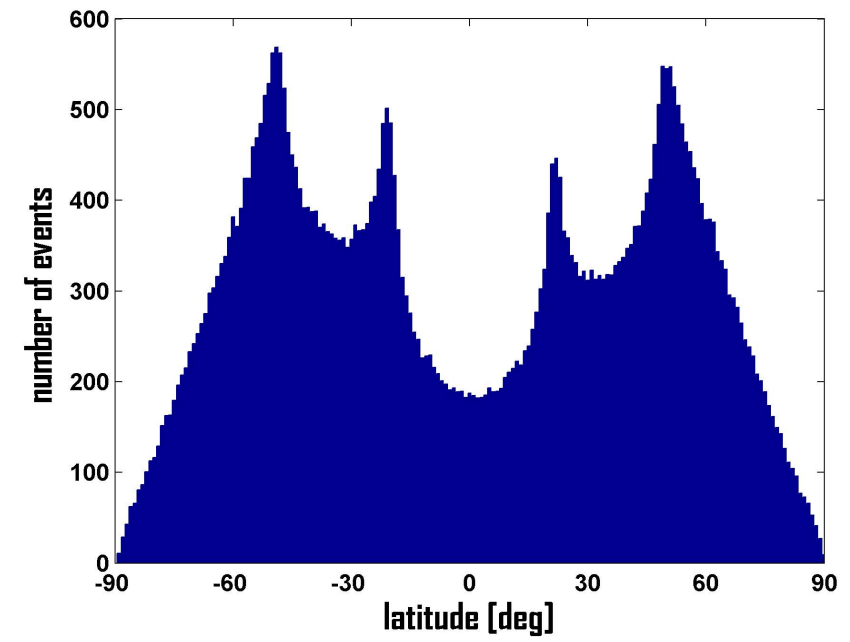

Fig. 1. COSMIC radio occultation coverage. Monthly latitudinal distribution of COSMIC occultations in 2009.

(ACES) payload (Svehla et al., 2006). It will be mounted on the external platform of the Columbus laboratory module, viewing towards the limb in the forward direction. The inclination of ISS orbit $\left(51.6^{\circ}\right)$ will allow the ACES GPS receiver to monitor the major convective regions of the Earth contributing to increase the number of GPS RO within the tropical regions by $32 \%$ (Fig. 2). We have selected all the RO profiles from the above-mentioned missions during the period 1995-2009, analysed them, and compared them with co-located data along the TC best tracks. The Geostationary Operational Environmental Satellite (GOES) brightness temperature (BT) were analysed near the location of the RO profiles in order to detect the overshooting during the TCs. Although GPS RO observations are not sensitive to the small amounts of water vapor in the UTLS, the bending angle and the temperature profiles show a clear signature of the convection in the UTLS which is confirmed by the comparison with co-located radiosonde (RAOB) data.

\section{Data description}

The TCs best tracks were collected from different sources: US National Hurricane Center (Atlantic, Caribbean, Gulf of Mexico and Eastern Pacific), Australian Government Bureau of Meteorology (Western, Northern and Eastern Australia), Japan Meteorological Agency (Western and Northern Pacific), Meteo France (Southwest Indian Basin) and Unysis Weather (North Indian Ocean Basin, Bay of Bengal and Arabian Sea). All these institutes provide information every $6 \mathrm{~h}$, including at least the name, dates, coordinates, minimum pressure, maximum wind speed and category of the tropical cyclone. In some cases, during the Hurricane Hunters missions, additional information is available, such as eye dimension, moving cyclone direction and speed.
Table 1. Number of profiles (second column) analysed and number of coincidences between GPS radio occultation and tropical cyclones in a time window of $3 \mathrm{~h}$ and a space window of $300 \mathrm{~km}$ (third column).

\begin{tabular}{lrr}
\hline Mission & \# profiles & RO - TC \\
\hline GPSMET (1995-1997) & 5002 & 1 \\
SAC-C (2001-2002) & 60354 & 40 \\
CHAMP (2001-2008) & 397193 & 180 \\
COSMIC (2006) & 249923 & 179 \\
COSMIC (2007) & 614201 & 194 \\
COSMIC (2008) & 641440 & 335 \\
COSMIC (2009) & 644035 & 211 \\
GRACE (2007-2009) & 113567 & 54 \\
\hline Total & 2725715 & 1194 \\
\hline
\end{tabular}

The RAOBs in FSL (Forecast System Laboratory) format, are part of the National Oceanic and Atmospheric Administration Earth System Research Laboratory (NOAA-ESRL) radiosonde database, and they are used as in situ validation of RO temperature and water vapour mixing ratio profiles.

Tropopause climatology is used as reference to detect if the convection reaches the TTL or not. For this purpose we used the climatological tropopause height from National Centers for Environmental Prediction (NCEP) analyses, containing monthly mean zonally averaged tropopause heights. This encompasses $40 \mathrm{yr}$ of data starting in January 1958 with latitudinal resolution of 2.5 degrees.

The GPS ROs that we have analyzed were downloaded from the COSMIC Data Analysis and Archive Center (CDAAC) website. We collected all the GPS/MET, SACC, CHAMP, GRACE and COSMIC profiles as shown in Table 1 . The results of this work are obtained using level 2 data products in netCDF format:

- atmPrf, which is an atmospheric profile without moisture information, containing coordinates and mean sea level altitude of the perigee point, dry pressure and temperature (derived assuming no water vapour), refractivity, bending angle and impact parameter.

- wetPrf, which is an interpolated product obtained using 1DVar (one dimensional variational) technique with a vertical resolution of $100 \mathrm{~m}$, containing latitude and longitude of the perigee point, pressure, temperature, water vapour pressure, refractivity and mean sea level altitude of the perigee point.

- sonPrf, which is radiosonde data co-located with the GPS RO (time window of $6 \mathrm{~h}$ and space window of $400 \mathrm{~km}$ ) containing latitude, longitude, pressure, temperature, water vapour pressure, refractivity and mean sea level geometric height. 
The GOES brightness temperature analyses were used as a detector of overshoots. We downloaded from the Comprehensive Large Array Data Stewardship System (CLASS) the GOES VARiable IMaGer data (GVAR_IMG) in "area" format with native spatial resolution acquired by GOES 11 and GOES12. Using the BT at 6.8 microns (band 3), which is sensitive to the water vapour, and the $\mathrm{BT}$ at 10.7 microns (band 4), it is possible to detect convective systems (Schmetz et al., 1997; Chaboureau et al., 2007). In clear sky conditions and low level clouds, the BT in the water vapour channel is lower than the BT at 10.7 microns. When the overshoot is present, there is an inversion and the BT at 6.8 microns becomes larger by a few degrees. GOES data were also used to detect if the RO and the RAOB were acquired in the same meteorological conditions.

\section{Methods}

The GPS receivers measure the phase and amplitude of two L-band signals. Using these it is possible to get the bending angle, which is used to compute the refractivity through Abel inversion (Kuo et al., 2004). Temperature, pressure and water vapour are derived from the refractivity and the European Centre for Medium-Range Weather Forecasts (ECMWF) model, using a one-dimensional variational (1DVar) method. In the 1DVar approach at CDAAC, much more weight is given to the refractivity observation than to the ECMWF model, ensuring that the derived temperature $(T)$, pressure $(p)$ and water vapour $(e)$ are basically consistent with the observed refractivity $(N)$ according to the equation

$N=77.6 \frac{p}{T}+3.73 \cdot 10^{5} \frac{e}{T^{2}}$

Thus, the physical relation between the solution and the observed refractivity is preserved, and the temperature is basically the same as the so-called dry temperature in regions where moisture is insignificant. The approach still includes information from ECMWF fields to separate out the meteorological variables in the moist troposphere, but it seeks to minimize the influence from the ECMWF fields and it preserves the full information coming from the observations.

One of the parameters that we analyze and discuss in this paper is the bending angle (raw, unoptimized) percentage anomaly with respect to the climatology (Biondi et al., 2011). This is defined as

$100 \cdot\left(\alpha_{\mathrm{TC}}-\alpha_{\mathrm{Clim}}\right) / \alpha_{\mathrm{Clim}}$,

where $\alpha_{\mathrm{TC}}$ is the bending angle value during the TC and $\alpha_{\text {Clim }}$ is the climatological bending angle from the gridded reference described in the next section.

When it is possible, we use the co-located RAOB profiles as in situ reference for temperature and water vapor profiles.

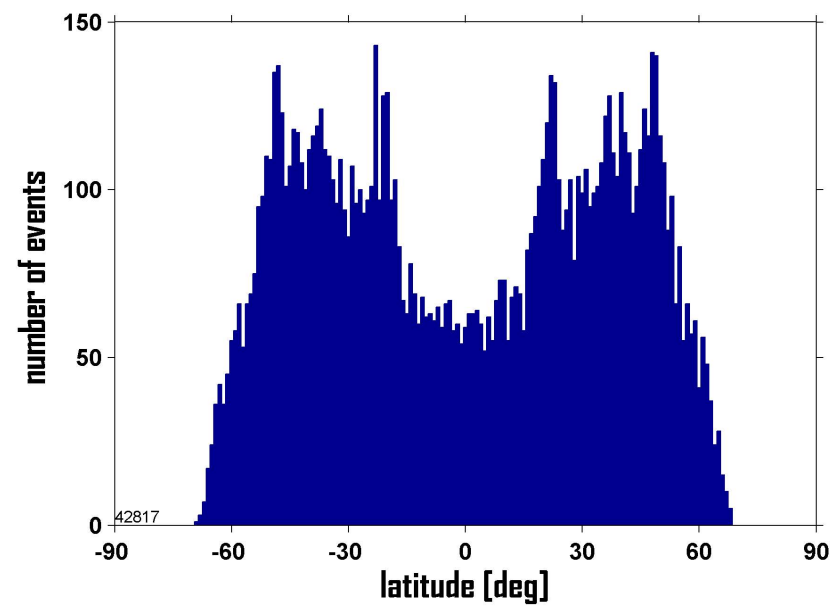

Fig. 2. ACES radio occultation coverage. Simulated monthly latitudinal distribution of ACES occultations.

We use the GOES data to monitor the position of the radio occultation and the RAOB relative to the position of the TC and to detect if overshoots can be expected in the same area.

\section{Statistics}

Using all the GPS ROs collected from the CDAAC website (covering the period 1995-1997 and 2001-2009), we have created a grid with one-degree resolution containing the averaged bending angle profiles. Any mean profile is the average result of a certain number of ROs depending on the coordinates. This grid will be our climatology reference for all the analyses. Comparing all the GPS ROs with the TC tracks, we have found 1194 coincidences (Table 2) within a time window of $3 \mathrm{~h}$ and a space window of $300 \mathrm{~km}$ between the TC center and the RO tangent point at $15 \mathrm{~km}$ of altitude (this is our reference altitude since we are studying the UTLS). The majority of the coincidences are coming from the COSMIC mission (77\%), $15 \%$ from CHAMP, $4.5 \%$ from GRACE, $3.4 \%$ from SACC and just 1 profile from GPS/MET. Fig. 3 shows the averaged bending angle anomaly for the 1194 cases together with the standard deviation of the mean. During the storms 3 distinct regions are clearly recognizable, each with different trends: the lower troposphere (between 3 and $8 \mathrm{~km}$ ), the mid troposphere and the UTLS (usually between 14 and $18 \mathrm{~km}$ ). In the lower troposphere there is an increase of the bending angle anomaly due to the combined effect of the increase of water vapor (which prevails) pushed up by the convection and the warming due to the instability of the TC. Moving to higher altitudes, the water vapor content decreases and the contribution of the temperature prevails. We have not deepened the study of the negative bending angle anomaly just below the top of the TC (between $10 \mathrm{~km}$ and $14 \mathrm{~km}$ of altitude). 
Table 2. Number of coincidences between GPS radio occultation and tropical cyclones in a time window of $3 \mathrm{~h}$ and a space window of $300 \mathrm{~km}$, for each year and each mission.

\begin{tabular}{|c|c|c|c|c|c|c|}
\hline & GPSMET & SACC & CHAMP & COSMIC & GRACE & Total \\
\hline 1995 & 1 & & & & & 1 \\
\hline 2001 & & 13 & 9 & & & 22 \\
\hline 2002 & & 27 & 28 & & & 55 \\
\hline 2003 & & & 29 & & & 29 \\
\hline 2004 & & & 40 & & & 40 \\
\hline 2005 & & & 33 & & & 33 \\
\hline 2006 & & & 12 & 179 & & 191 \\
\hline 2007 & & & 9 & 194 & 18 & 221 \\
\hline 2008 & & & 20 & 335 & 22 & 377 \\
\hline 2009 & & & & 211 & 14 & 225 \\
\hline Total & 1 & 40 & 180 & 919 & 54 & 1194 \\
\hline
\end{tabular}

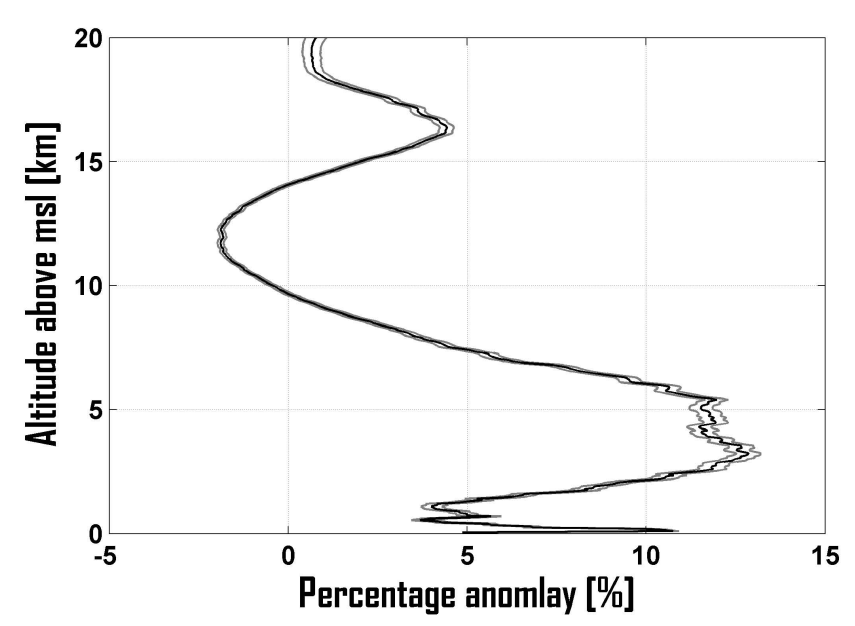

Fig. 3. Averaged bending angle anomaly profile for 1194 TC cases from 1995 to 2009 (black line) \pm the standard deviation of the mean (grey lines).

The increase of the bending angle anomaly in the UTLS, is completely due to the temperature variation since the water vapor content amount is usually extremely low. The bending angle anomaly between 14 and $18 \mathrm{~km}$ of altitude is negative outside of the tropical cyclone season and it becomes positive during the tropical cyclone season reaching the highest intensity during the storm (Biondi et al., 2011).

A histogram showing the maximum anomaly during tropical cyclones is shown in Fig. 4. We can clearly see that more than $60 \%$ of the cases present maximum anomaly between $5 \%$ and $15 \%$ greater than the climatology. Just 15 cases do

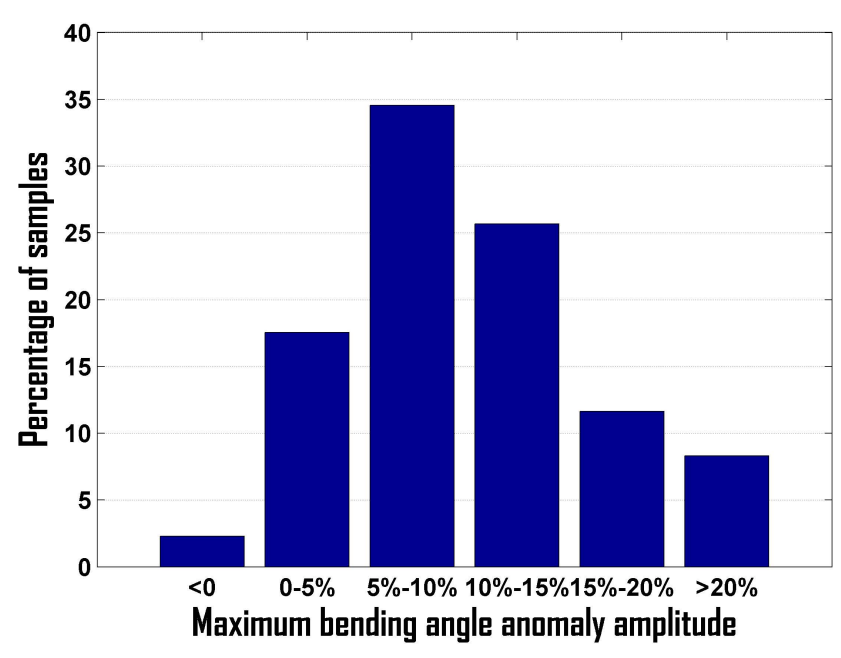

Fig. 4. Distribution of positive peak bending angle anomalies between 14 and $18 \mathrm{~km}$ during TCs.

not present any positive anomaly spike in the UTLS, in these cases we do not have additional information regarding the size of the cyclone and we suppose that they were probably not acquired inside the storm. Figure 5 shows the distribution of mean negative anomaly between 14 and $18 \mathrm{~km}$ during TCs, where $81 \%$ of the cases reveal a positive anomaly. During normal conditions (Fig. 6), i.e., in the absence of TCs, the probability to get positive or negative anomaly in the same areas of the globe is evenly distributed. This is because in normal conditions we include clear sky acquisitions but also many storms not selected as TCs. 


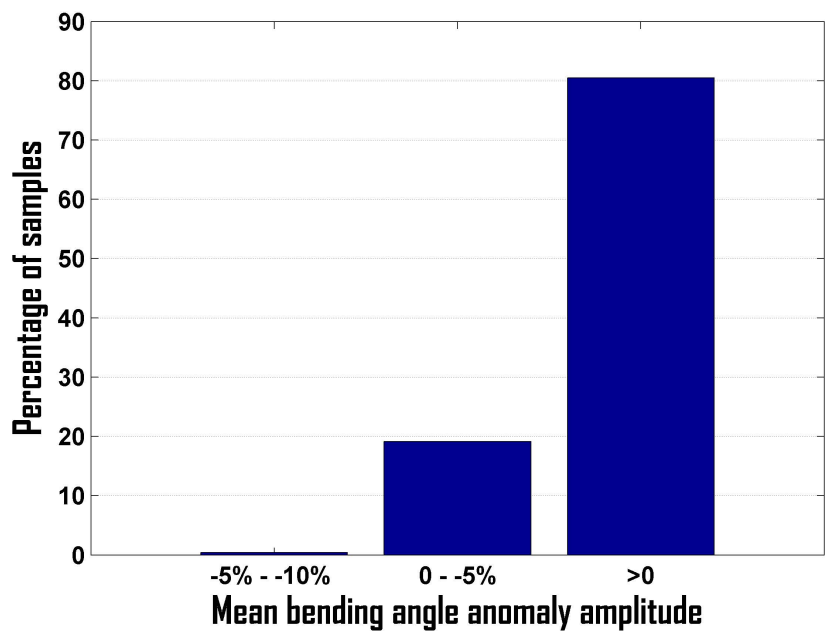

Fig. 5. Distribution of mean negative bending angle anomalies between 14 and $18 \mathrm{~km}$ during TCs.

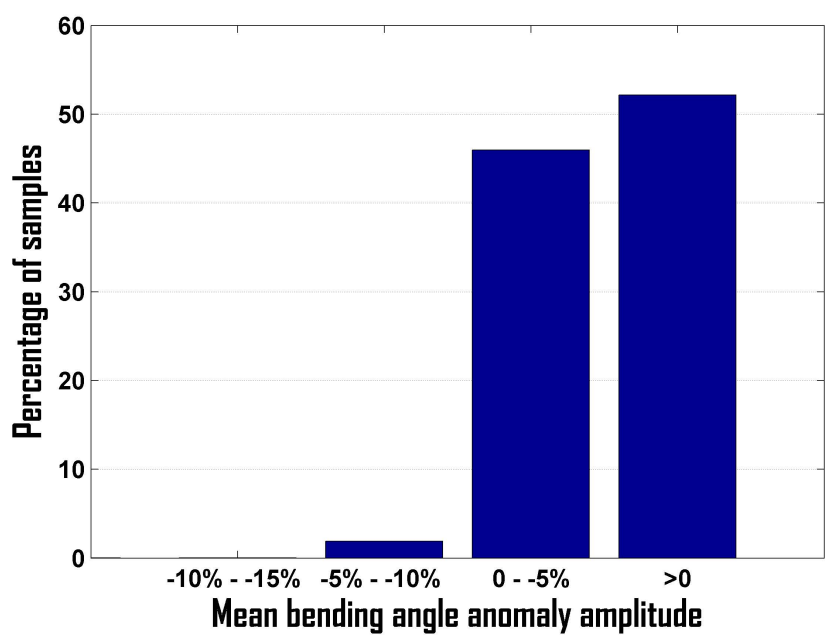

Fig. 6. Distribution of mean negative bending angle anomalies between 14 and $18 \mathrm{~km}$ during normal conditions, i.e., in the absence of TCs.

\section{Profiles analyses}

Analyzing the RAOB temperature profiles during the TCs, we can see two clear minima at the tropopause altitude. The comparison with the co-located bending angle anomaly shows two positive spikes at the same altitude of the two temperature minima. Similar features are often evident also in the RO temperature profile, but sometimes it is not as clearly seen as it is in the bending angle anomaly.

Figure 7 illustrates the situation during the TC Bill. The RO was acquired on 22 August 2009 at 08:27:00 UTC in the Atlantic Ocean when Bill was weakening from hurricane category 3 to hurricane category 2 . The radiosonde was launched at 11:00:00 UTC and the distance between the radiosonde station (Bermuda airport) and the RO tangent point at $15 \mathrm{~km}$ altitude was $98.32 \mathrm{~km}$.

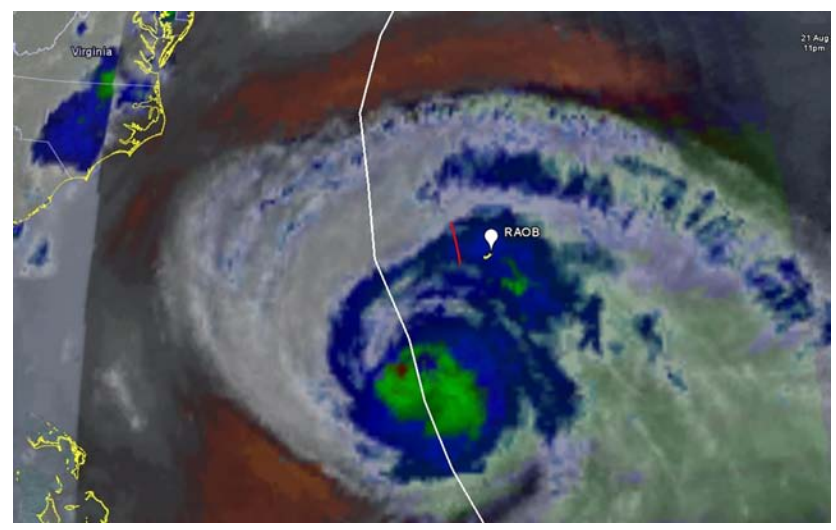

Fig. 7. Tropical cyclone Bill on 22 August 2009 with the co-located radiosonde (white balloon) and radio occultation (red line).

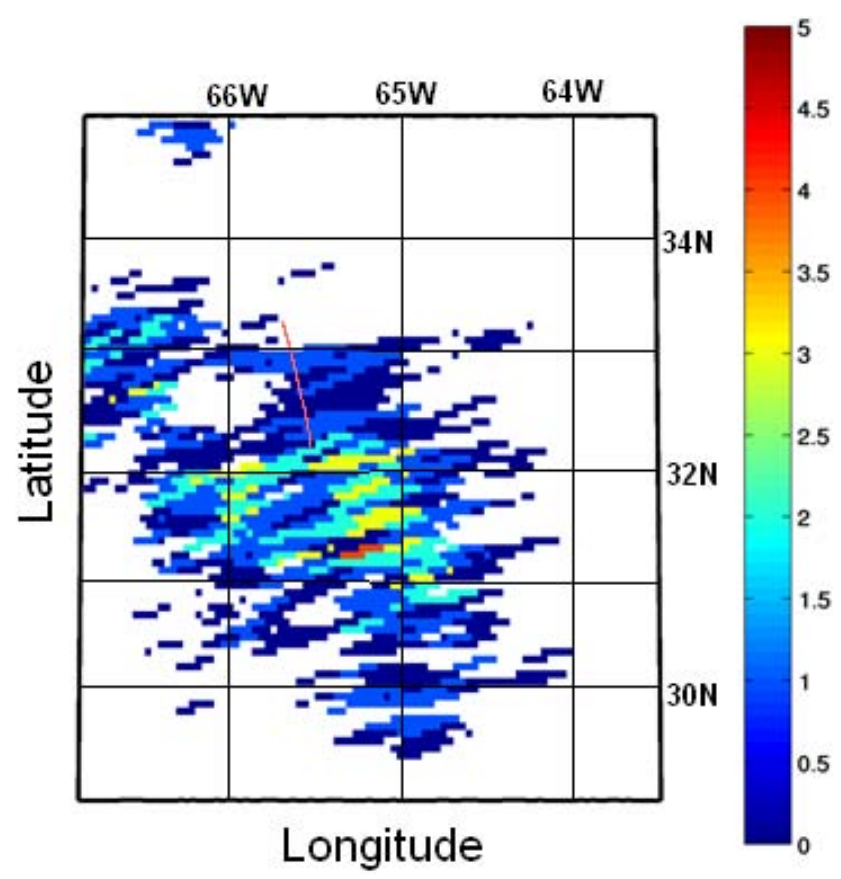

Fig. 8. Event Bill 22 August 2009, 08:27:00 UTC, (Latitude $32^{\circ} 30^{\prime}$ and Longitude $-65^{\circ} 42^{\prime}$ ): difference between the brightness temperature (BT) at 6.8 microns and the $\mathrm{BT}$ at 10.7 microns (BT in Kelvin) from GOES 11. The red line indicates the projection of the RO tangent points.

Figure 8 shows the difference of the BT at 6.8 microns and the BT at 10.7 microns from GOES11 in the same region where the RO and the RAOB were acquired. An inversion is present; consequently some overshoot should be expected.

The RAOB temperature profile shows a double minimum, the lowest exactly at the standard tropopause altitude and the second one at about $18.6 \mathrm{~km}$ (Fig. 9). The local temperature variation is larger than $5 \mathrm{~K}$ and this defines an evident double tropopause. The bending angle anomaly, as usual during TCs, has two local maxima, the lowest one $10 \%$ larger than 


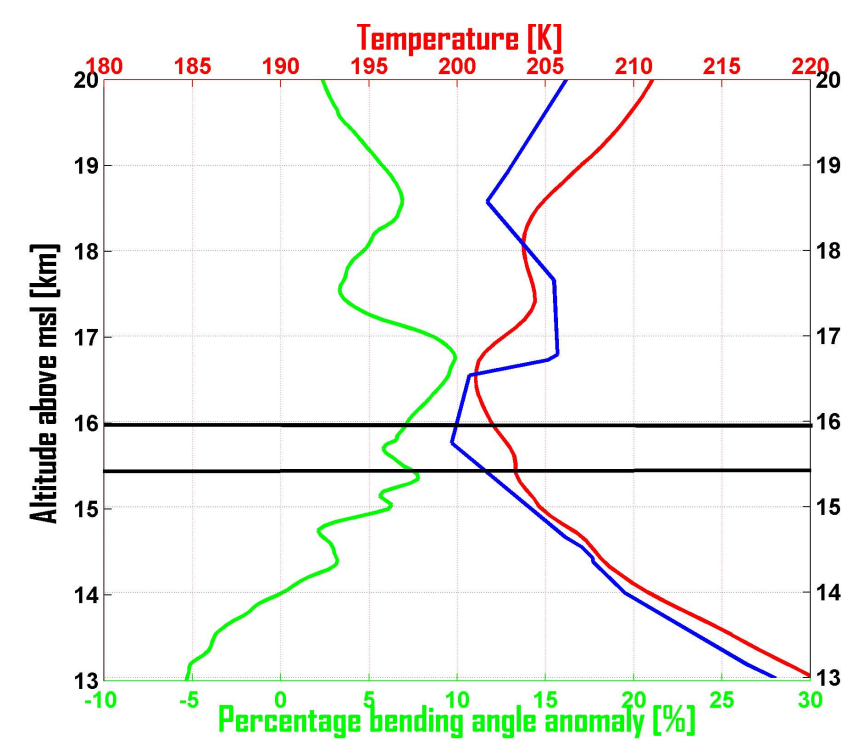

Fig. 9. Event Bill 22 August 2009, 08:27:00 UTC: temperature profiles and bending angle anomaly profile between 13 and $20 \mathrm{~km}$ of altitude. The green line is the bending angle anomaly profile, the blue line is the temperature from RAOB and the red line is the temperature from the RO. The horizontal black lines show the minimum and maximum standard tropopause altitude at those latitudes from NCEP 40 yr dataset.

the climatology in the same area (at $17 \mathrm{~km}$ of altitude), and the second one at about $18.6 \mathrm{~km}$. Within the uncertainty and limited vertical resolution of the RAOB, and considering that the two measurements are not exactly coincident, the spikes in the bending angle and temperature anomalies, as well as the minima in the RO temperature profile (although not as distinct) corresponds reasonably well to the minima in the RAOB temperature profile.

We show in Fig. 10 another case: the hurricane Bertha 2008. The RO was acquired on 12 July 2008 at 12:47:00 UTC in the Atlantic basin when Bertha was hurricane category 1. The radiosonde was launched at 12:00:00 UTC and the distance between the radiosonde station and the RO tangent point at $15 \mathrm{~km}$ altitude was about $170 \mathrm{~km}$.

In this case, corresponding to the double spike of the bending angle anomaly, the double temperature minima are clearly shown from the RO and the RAOB temperature profiles with perfect agreement.

The double spike of the bending angle anomaly at these altitudes is a common feature of the UTLS during TCs. So far, we have selected about 700 cases. In all the cases the lowest coldest point (and the warming about $1 \mathrm{~km}$ above) is clearly recognizable in the RO temperature profiles. In Fig. 11 we used as reference the altitude of the warming between the two tropopauses ( $\mathrm{Zo}$ ) and we plotted the averaged temperature anomaly and the bending angle anomaly $5 \mathrm{~km}$ below and above the reference Zo, from all the GPS ROs selected,. Five km below Zo, the troposphere is warmer than the clima-

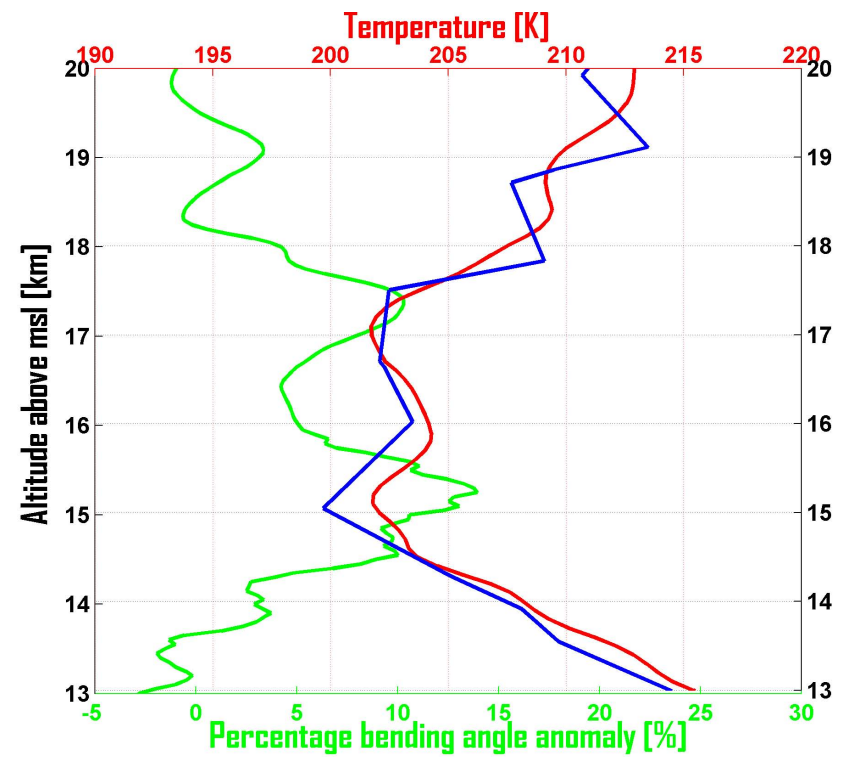

Fig. 10. Event Bertha 12 July 2008, 12:47:00 UTC: bending angle percentage anomaly (green) and corresponding temperature profile from RAOB (blue) and from RO (red), between 13 and $20 \mathrm{~km}$.

tology and the bending angle anomaly is negative. The first tropopause (lowest coldest point) corresponds to the lower spike of the bending angle and above Zo there is a new decrease of the temperature corresponding to the bending angle increase. The amplitude of the highest coldest point (and bending angle spike) is not so large as the lower one, since the second tropopause does not occur always at the same vertical distance from the warming.

We have found 246 co-located RAOBs reaching the UTLS and $90 \%$ of these cases show a temperature double minima in correspondence with the double spike of the bending angle.

The double local minima detected during our studies, confirms the results of Danielsen (Danielsen, 1982, 1993) explaining the lowest one as the mean tropopause and the highest one as the cold stratospheric anvil produced by the deep convection. The same temperature trend has been clearly recognized with in situ measurements during the Tropospheric/Stratospheric Water Vapor Exchange Experiment (TSWVEE) (Kley et al., 1982) and the Tropical Convection, Cirrus and Nitrogen Oxides (TROCCINOX) (Chaboureau, 2007).

\section{Conclusions}

Our results show that the bending angle from the GPS RO signal contains interesting information on the tropopause during TCs. In general the bending angle anomaly relative to the climatology is positive during tropical cyclone season in the UTLS and the magnitude of the anomaly increases during 


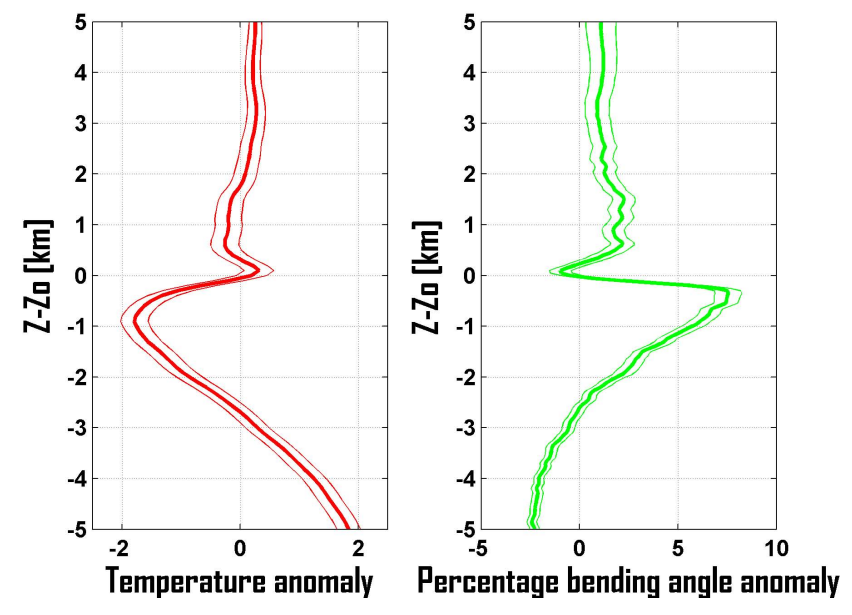

Fig. 11. Averaged temperature anomaly (bold red line, right panel) \pm the standard deviation of the mean and bending angle percentage anomaly (bold green line, left panel) \pm the standard deviation of the mean, $5 \mathrm{~km}$ below and above the warming altitude (Zo) occurring between the 2 tropopauses.

a TC. This variation of anomaly is not enough to detect convective towers since it could be due to a simple reduction of the tropopause temperature, but it is anyway a clear signature of the TC. Extending the analysis to using RAOBs, during strong convective events a double tropopause is often recognized and the bending angle anomaly can be used to detect it. In this way the bending angle can be used as an indicator of convective towers. Our results suggest that ACES missions on board of ISS will increase the RO measurements in the tropics providing important support to the study of TCs and the study of overshoots.

Acknowledgements. We would like to thank G. Beyerle for the ACES simulator.

Edited by: A. K. Steiner

\section{References}

Anthes, R. A., Bernhardt, P. A., Chen, Y., Cucurull, L., Dymond, K. F., Ector, D., Healy, S. B., Ho, S.-H., Hunt, D. C., Kuo, Y.-H., Liu, H., Manning, K., McCormick, C., Meehan, T. K., Randel, W. J., Rocken, C., Schreiner, W. S., Sokolovskiy, S. V., Syndergaard, S., Thompson, D. C., Trenberth, K. E., Wee, T.-K., Yen, N. L., and Zeng, Z.: The COSMIC/Formosat/3 mission: Early results, B. Amer. Meteor. Soc., 89, 313-333, 2008.

Beyerle, G., Schmidt, T., Michalak, G., Heise, S., Wickert, J., and Reigber, Ch.: GPS radio occultation with GRACE: Atmospheric Profiling utilizing the zero difference technique, Geophys. Res. Lett., 32, L13806, doi:10.1029/2005GL023109, 2005.

Biondi, R., Neubert, T., Syndergaard, S., and Nielsen, J.: Measurements of the upper troposphere and lower stratosphere during tropical cyclones using the GPS radio occultation technique, Adv. Space Res., 47, 348-355, 2011.
Cairo, F., Buontempo, C., MacKenzie, A. R., Schiller, C., Volk, C. M., Adriani, A., Mitev, V., Matthey, R., Di Donfrancesco, G., Oulanovsky, A., Ravegnani, F., Yushkov, V., Snels, M., Cagnazzo, C., and Stefanutti, L.: Morphology of the tropopause layer and lower stratosphere above a tropical cyclone: a case study on cyclone Davina (1999), Atmos. Chem. Phys., 8, 34113426, doi:10.5194/acp-8-3411-2008, 2008.

Chaboureau, J.-P., Cammas, J.-P., Duron, J., Mascart, P. J., Sitnikov, N. M., and Voessing, H.-J.: A numerical study of tropical crosstropopause transport by convective overshoots, Atmos. Chem. Phys., 7, 1731-1740, doi:10.5194/acp-7-1731-2007, 2007.

Chae, J. H., Wu, D. L., Read, W. G., and Sherwood, S. C.: The role of tropical deep convective clouds on temperature, water vapor, and dehydration in the tropical tropopause layer (TTL), Atmos. Chem. Phys., 11, 3811-3821, doi:10.5194/acp-11-38112011, 2011.

Danielsen, E. F.: A dehydration mechanism for the stratosphere, Geophys. Res. Lett., 9, 605-608, 1982.

Danielsen, E. F.: In situ evidence of rapid, vertical, irreversible transport of lower tropospheric air into the lower tropical stratosphere by convective cloud turrets and by larger-scale upwelling in tropical cyclones, J. Geophys. Res., 98, 8665-8681, 1993.

Forster, P. M. and Shine, K. P.: Stratospheric water vapour changes as a possible contributor to observed stratospheric cooling, Geophys. Res. Lett., 26, 3309-3312, 1999.

Forster, P. M. and Shine, K. P.: Assessing the climate climate impact of trends in stratospheric water vapor, Geophys. Res. Lett., 29, 101-102, 2002.

Fueglistaler, S., Dessler, A. E., Dunkerton, T. J., Folkins, I., Fu, Q., and Mote, P. W.: Tropical tropopause layer, Rev. Geophys., 47, RG1004, doi:10.1029/2008RG000267, 2009.

Hajj, G. A., Ao, C. O., Iijima, B. A., Kuang, D., Kursinski, E. R., Mannucci, A. J., Meehan, T. K., Romans, L. J., de La Torre Juarez, M., and Yunck, T. P.: CHAMP and SAC-C atmospheric occultation results and intercomparisons, J. Geophys. Res., 109, D06109, doi:10.1029/2003JD003909, 2004.

Kim, H. C.: The effect of deep convection on temperatures in the tropical tropopause layer and its implications to the regulation of tropical lower stratospheric humidity, $\mathrm{PhD}$ Thesis, University of Houston, USA, 2005.

Kley, D., Schmeltekopf, A. L., Kelly, K., Winkler, R. H., Thompson, T. L., and McFarland, M.: Transport of water through the tropical tropopause, Geophys. Res. Lett., 9, 617-620, 1982.

Kuo, Y. H., Wee, T. K., Sokolovskiy, S., Rocken, C., Schreiner, W., Hunt, D., and Anthes, R. A.: Inversion and error analysis of GPS radio occultation data, J. Meteor. Soc. Japan, 82, 507-531, 2004

Kursinski, E. R., Hajj, G. A., Schofield, J. T., Linfield, R. P., and Hardy, K. R.: Observing Earth's atmosphere with radio occultation measurements using the Global Positioning System, J. Geophys. Res., 102, 23429-23465, 1997.

Manabe, S. and Wetherald, R. T.: Thermal equilibrium of the atmosphere with a given distribution of relative humidity, J. Atmos. Sci., 24, 241-259, 1967.

Ray, E. A. and Rosenlof, K. H.: Hydration of the upper troposphere by tropical cyclones, J. Geophys. Res., 112, D12311, doi:10.1029/2006JD008009, 2007.

Rocken C., Anthes, R., Exner, M., Hunt, D., Sokolovskiy, S., Ware, R., Gorbunov, M., Schreiner, W., Feng, D., Herman, B., Kuo, Y.-H., and Zou, X.: Analysis and validation of GPS/MET data in 
the neutral atmosphere, J. Geophys. Res., 102, 298490-29860, 1997.

Romps, D. M. and Kuang, Z.: Overshooting convection in tropical cyclones, Geophys. Res. Lett., 36, L09804, doi:10.1029/2009GL037396, 2009.

Schmetz, J., Tjembs, S. A., Gube, M., and Van de Berg, L.: Monitoring deep convection and convective overshooting with Meteosat, Adv. Space Res., 19, 433-441, 1997.

Sherwood, S. C., Horinouchi, T., and Zeleznik, H. A.: Convective impact on temperatures observed near the tropical tropopause, J. Atmos. Sci., 60, 1847-1856, 2003.

Soden, B. J. and Fu, R.: A satellite analisys of deep convection, upper tropospheric humidity and the greenhouse effect, J. Clim., 8, 2333-2351, 1995.
Solomon, S., Rodenlof, K., Portmann, R., Daniel, J. S., Davis, S. M., Sanford, T. J., and Plattner, G. K.: Contribution of stratospheric water vapor to decadal changes in the rate of global warming, Sciencexpress, 327(5970), 1219-1223, doi:10.1126/science.1182488, 2010.

Svehla, D., Rothacher, M., Ziebart, M., and Salomon, C.: Galileo on board International Space Station and synergy with the ACES clock ensemble, EGU General Assembly, 2006.

Wickert, J., Reigber, C., Beyerle, G., König, R., Marquardt, C., Schmidt, T., Grundwaldt, L., Galas, R., Meehan, T. K., Melbourne, W. G., and Hocke, K.: Atmosphere sounding by GPS radio occultation: First results from CHAMP, Geophys. Res. Lett., 28, 3263-3266, 2001. 